\title{
Long Term Dynamic of Power System with renewable energy sources and energy storage systems
}

\author{
K. Máslo ${ }^{1}$, A. Kasembe ${ }^{2}$ \\ ${ }^{1}$ Department of Transmission System Analysis \\ ${ }^{2}$ Department of System Development \\ ČEPS,a.s \\ Elektrárenská 774/2, 10152 Prague (Czech Republic) \\ e-mail: maslo@ceps.cz,kasembe@ceps.cz
}

\begin{abstract}
This paper deals with the long term dynamic simulation of a power system from the load frequency control point of view. The power system consists of conventional sources together with renewable sources and energy storage systems (batteries). Different options and rules for frequency restoration reserves activation and batteries control are considered.
\end{abstract}

\section{Key words}

Energy Storage System (ESS), Load Frequency Control (LFC), Renewable Energy Sources (RES)

\section{Introduction}

The paper [1] dealt with a power system dynamics from transmission system development point of view. It considered replacing of conventional sources by renewable sources and an energy storage system (ESS) was used to solve daily load diagram peak shaving and for saving the regulation energy.

This paper deals with the load frequency control in the power system with RES (especially with photovoltaics) and ESS (batteries). Both regimes - island operation and synchronous interconnection are considered for the power system operation. Two rules for dispatching of units providing secondary control reserves (or frequency restoration reserves according to the new terminology estabilished in EU guidline [2]) are described. The first rule is the common used pro-rata method. The second rule is a merit -order activation mentioned also in [2].

The simulation on a dynamic model is used for investigation of the power system behaviour with different shares of RES, regimes of system operation and activation rules of the controlled units. Since models (and data) of real power system are confidential, in this paper publicly available and well known IEEE RTS test system is used.

The MODES network simulator is used as the computation tool (see e.g. [3] - [6]).

\section{Dynamic model description}

Requirements for long term dynamic models suitable for one day simulation of the power system operation are described in [1].The focus in this paper is only on some important parts of the long term dynamic modelling lasting one day or more.

\section{A. Load modelling}

Variable load can be modelled in dependency on the daily time $\mathrm{T}$ and the week order $\mathrm{W}$ according to the equation:

$$
\mathrm{P}=\mathrm{P}_{\text {str }}\left(1+\sum_{\mathrm{i}=1}^{4} A_{i} \sin \left(\mathrm{iT} \times \pi / 12+\varphi_{i}\right) *\left(1+\sum_{\mathrm{i}=1}^{2} A_{W i} \sin \left(\mathrm{iW} \times \pi / 26+\varphi_{W i}\right)\right.\right.
$$

where $P_{s t r}$ is mean value of the load, A and $\varphi$ are model parameters.

\section{B. Photovoltaics (PV) modelling}

$\mathrm{PV}$ are characterized by fluctuations in output power $\mathrm{P}_{\mathrm{PV}}$ according to the modified sun insolation curve model [7] in dependency on the daily time $\mathrm{T}$ and the week order $\mathrm{W}$ according to the equation:

$$
\mathrm{P}_{P V}=\mathrm{P}_{P V p}\left(A+A_{1} \sin \frac{\mathrm{W} \pi}{52}\right) e^{-0.5\left(\frac{|\mathrm{T}-\mu|}{\sigma+\sigma_{1} \sin \frac{\mathrm{W} \pi}{52}}\right)^{3}}
$$

$\mathrm{P}_{\mathrm{PVp}}$ is installed peak power. $A, \mu$ and $\sigma$ are the model parameters.

\section{Energy Storage System (ESS) modelling}

A detailed ESS model is described in the Appendix.

The basis of the model is the relationship between the charge and discharge power $\mathrm{P}$ and the stored energy Es. 
The relations are as follow:

$$
\begin{array}{cc}
\mathrm{T}_{E S S} \frac{d E_{S}}{d t}=-\frac{P}{\eta_{D}} & \text { for } \mathrm{P}>0 \text { (discharging) } \\
\mathrm{T}_{E S S} \frac{d E_{S}}{d t}=-\eta_{C} P \quad \text { for } \mathrm{P}<0 \text { (charging) }
\end{array}
$$

$\mathrm{T}_{\mathrm{ESS}}$ is time constant, which defines ESS capacity, $\eta_{C}, \eta_{D}$ are charge and discharge efficiencies.

ESS power is controlled depending on desired objective, for example peak shaving loads, removing line overloads, frequency control and/or synthetic inertia providing.

\section{Load frequency control (LFC) modelling}

The following figure shows a simple LFC model:

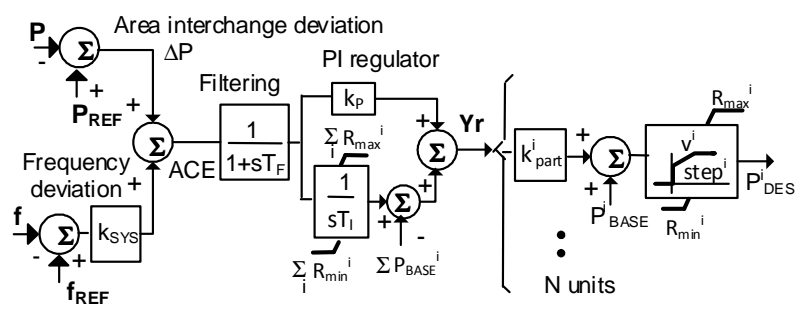

Fig. 1. Block scheme of the LFC model

The LFC model evaluates the area control error ACE. The value $\Delta \mathrm{P}$ is zero and the $\mathrm{LFC}$ is in so called flat control mode (it controls only the system frequency f) for the island operation. The output from the PI regulator $\mathrm{Yr}$ is divided by the participation coefficient $k_{\text {part }}$ into the individually controlled units that provide the frequency restoration reserves FRR. $\mathrm{P}_{\mathrm{BASE}}$ is the basic unit output resulting from the participation of the unit in the electricity market.

The participation coefficients are calculated in dependency on activation of FRR. The common way is a pro-rata activation: the proportional distribution of the controller output to the controlled units according to this rule:

$k_{\text {part }}^{i}=\frac{F R R^{i}}{\sum_{i} F R R^{i}} \quad F R R^{i}=\left(R_{\text {max }}^{i}-R_{\text {min }}^{i}\right) / 2$

where $R_{\max }-R_{\min }$ is a regulation range.

The second way is a merit-order activation, when the units with cheaper FRR are loaded preferentially (see e.g. [8]). The participation coefficients are calculated according to algorithms depicted in Fig. 2.

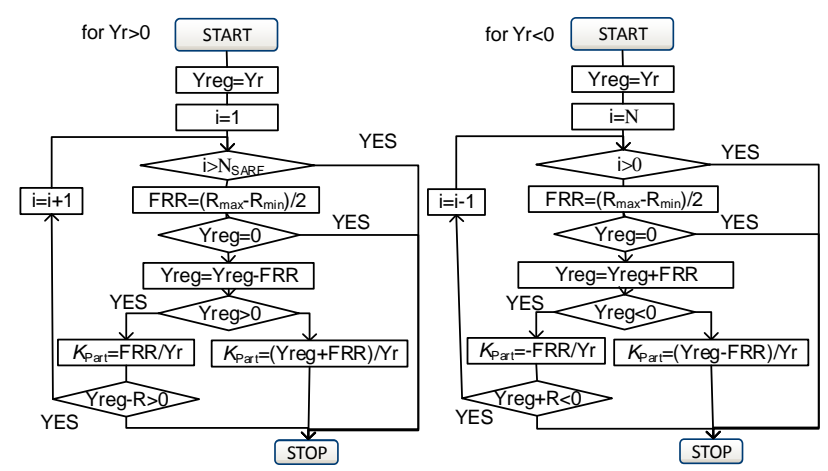

Fig. 2. Participation coefficients calculations
The controlled units are sorted by ascending price ( $\mathrm{i}=1$ for the cheapest and $\mathrm{i}=\mathrm{N}$ for the most expensive).

\section{Test system}

IEEE RTS 1996 [9] was used for testing of the long term simulation. One area of this system is depicted in Fig. 3.

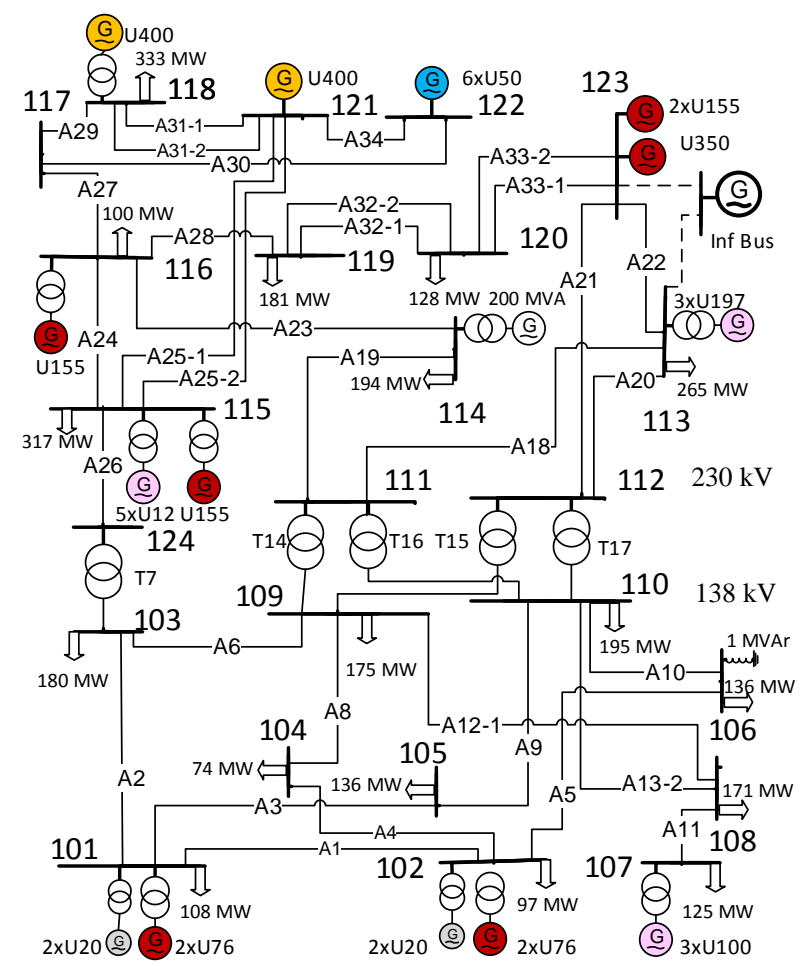

Fig. 3. One line diagram of the IEEE RTS test system

The one area system is suitable for the so called island operation, when the system is disconnected from a bulk power system. In the case of interconnected operation the system was extended by two tie-lines with the bulk power system (two dashed lines from the nodes 113 and 123) in the diagram above. The parameters of the test system was published in [1] and [9]. For the publication on ICREPQ'19, the system was slightly modified. The total load was increased to $119 \%$ with the peak load about 3380 MW. This increase was mostly covered by new photovoltaics with the installed power $500 \mathrm{MW}$ (in the nodes number 104, 105, 108 - 110). The approximate coverage of the daily load diagram is shown in Fig. 4.

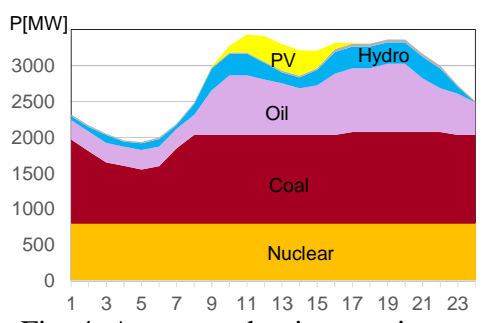

Fig. 4. Aggregated unit commitment

The units from Table I were used for LFC.

Table I. List of controlled units with regulation ranges

\begin{tabular}{|c|l|l|l|l|}
\hline Units & $3 \times$ U100 & 3 x U197 & 5 x U12 & 6 x U50 \\
\hline Fuel/Turbine & Oil/Steam & Oil/Steam & Oil/Steam & Hydro \\
\hline Range [MW] & 225 & 391 & 48 & 300 \\
\hline
\end{tabular}

Moreover an energy storage system $100 \mathrm{MW}$ (batteries with capacity $200 \mathrm{MWh}$ ) was installed in the node 101 to 
participate in daily load diagram covering. The batteries are charged during the night minimum load and they are discharged during peak load.

\section{Simulation results and discussion}

Two type of system operations were simulated. The first is an island operation and the second one is a parallel operation with bulk power system (interconnected operation).

\section{A. Island operation}

Two cases were simulated:

1. without ESS and

2. with ESS.

Charging and discharging of the ESS is controlled with the aim to peak shaving of the daily load diagram.

The measure of the quality of the load frequency control in the island is the frequency waveform. The following figure shows frequency deviations df for both cases.

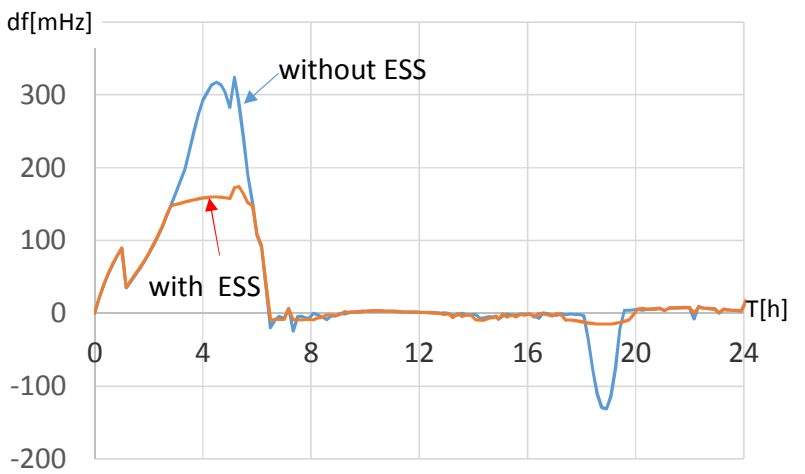

Fig. 5. Frequency deviation waveforms

ESS installation improved LFC quality and frequency stability significantly. Fig. 6 depicts ESS operation. Moreover it enables to remove the units U12 from LFC.

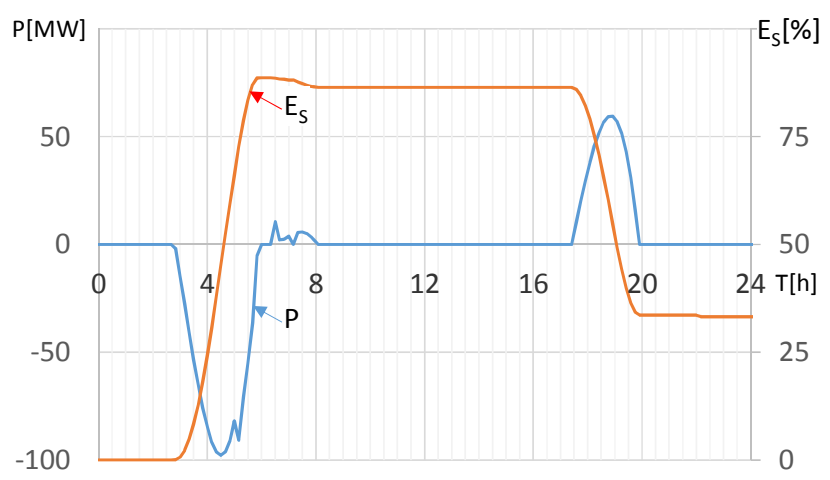

Fig. 6. ESS power $P$ and energy storage $E_{S}$

ESS started to charge before 3:00 and finished after 6:00 (charged to $88 \%$ ). It started to deliver power at 17:30 and finished before 20:00 (discharged to $33 \%$ ).

\section{B. Interconnected operation}

The test system from the above simulation is connected with a bulk power system through two tie lines (depicted by the dashed lines in Fig. 3). The LFC model evaluates the complete area control error ACE (practically it is the tie lines active power flow deviations from planned values $\Delta \mathrm{P}$, which correspond to unintentional power exchanges with the bulk power system) for the interconnected operation. The bulk power system was simulated by one equivalent generator modelled as an infinity bus (with the constant voltage and frequency).

Initial power imbalance in this operation is also maintained by unintentional power exchange (import or export) from the bulk system. That is, not only from rotating masses with frequency changes as in island operation. This is a great advantage of synchronous interconnection which is able to provide solidary assistance to cover power balance to the control areas. This feature enables the control area to decrease the FRR values comparing to the island operation.

Two cases were simulated:

1. without ESS,

2. with ESS and

Charging and discharging of the ESS is controlled with the aim to decrease unintentional power exchanges.

The measure of the quality of the load frequency control in the interconnected operation is indicated by the unintentional power exchange waveforms. The following figure shows power flow deviations $\Delta \mathrm{P}$ for both cases.

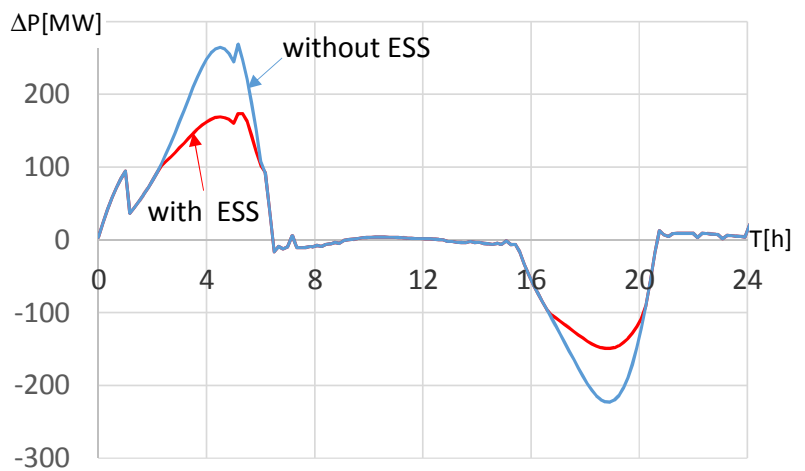

Fig. 7. Power flow deviation waveforms

It should be emphasized that the FRR has been reduced in comparison to the island operation (the range was reduced by a total of 189 MW). ESS installation improved LFC quality. Fig. 8 depicts ESS operation.

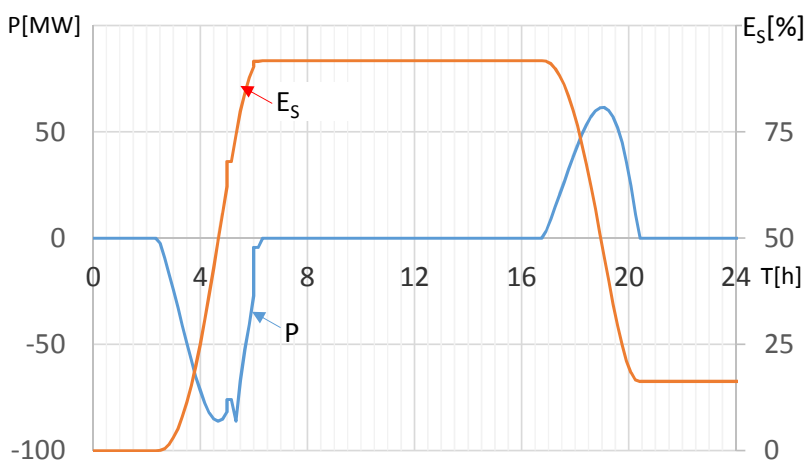

Fig. 8. ESS power $P$ and energy storage $E_{S}$ for the second case

ESS started to charge after 2:00 and finished at 6:00 (charged to $90 \%$ ). It started to deliver power at 17:00 and finished after 20:00 (discharged to 15\%). 
The LFC quality can be quantified by the mean square deviation $\sigma$ and maximum value of $\Delta \mathrm{P}$, which are summarized in the following table.

Table II. LFC quantitative evaluation for both cases

\begin{tabular}{|l|l|l|}
\hline & $\sigma \Delta \mathrm{P}[\mathrm{MW}]$ & $\Delta \mathrm{Pmax}[\mathrm{MW}]$ \\
\hline Without ESS & 112 & 268 \\
\hline With ESS & 82 & 175 \\
\hline
\end{tabular}

Previous calculations have been made with the pro-rata activation of the LFC units. If the merit order activation was used, the results were practically identical.

\section{Conclusions}

The paper presents the long term dynamic simulation of the power system from load frequency control (LFC) point of view. The dynamic model enables to investigate the LFC quality in dependence on different system operation (island or interconnected).

Using the energy storage system in the regulation improved the LFC quality, increased the frequency stability and enabled to decrease frequency restoration reserves. The way of frequency restoration reserves activation (pro-rata or merit order) did not significantly affect the dynamic behaviour of the tested system (it affects an economic efficiency, but it was not the subject of this paper).

\section{Appendix: ESS dynamic model}

The following figure shows block schemes of the EES model and an external regulator implemented in the MODES network simulator:

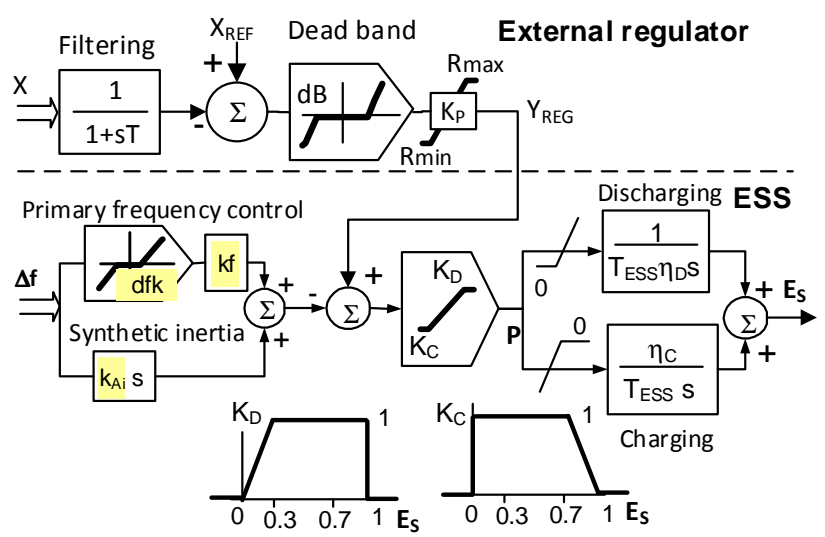

Fig. 9. ESS dynamic model together with the external regulator

The primary frequency and the synthetic inertia controls were not used in the simulation. The parameters of the ESS model were $T_{E S S}=2$ hours, $\eta_{C}=\eta_{D}=0.9 . P$ and $E_{S}$ are per unit values (the nominal ESS power is $100 \mathrm{MW}$ ).

The ESS model is controlled by a common external regulator (it can control any arbitrary variable) depicted in the upper part of the figure. Parameters are in Table III.

Table III. LFC quantitative evaluation for both cases

\begin{tabular}{|l|l|l|l|l|l|}
\hline Operation & $\mathrm{X}$ & $\mathrm{X}_{\mathrm{REF}}$ & $\mathrm{dB}$ & $\mathrm{K}_{\mathrm{P}}$ & $\mathrm{T}$ \\
\hline Island & $\mathrm{df}$ & $70 \mathrm{mHz}$ & $75 \mathrm{mHz}$ & $0.08 \mathrm{mHz}^{-1}$ & $60 \mathrm{~s}$ \\
\hline Interconnected & $\Delta \mathrm{P}$ & $0 \mathrm{MW}$ & $100 \mathrm{MW}$ & $0.0125 \mathrm{MW}^{-1}$ & $30 \mathrm{~s}$ \\
\hline
\end{tabular}

$\mathrm{Rmax}=-\mathrm{Rmin}=1$

\section{References}

[1] K. Máslo and A. Kasembe, "Extended long term dynamic simulation of power system", in Proc. $52^{\text {nd }}$ International Universities' Power Engineering Conference, 2017

[2] COMMISSION REGULATION (EU) 2017/2195 of 23 November 2017 establishing a guideline on electricity balancing, [On line] https://eur-lex.europa.eu/legalcontent/EN/TXT/?toc=OJ:L:2017:312:TOC\&uri=uriserv: OJ.L .2017.312.01.0006.01.ENG

[3] K. Máslo, "Advanced analysis of power system disturbances by the network simulator", in Proc. $9^{\text {th }}$ International scientific conference Electric Power Engineering 2008 , pp.177-182

[4] K. Máslo and M. Kolcun, "Simulation engine for dispatcher training and engineering network simulators", in Proc. IFAC CIGRE/CIRED Workshop on Control of Transmission and Distribution Smart Grids, 2016, [On line]. Available: https://www.sciencedirect.com/science/article/pii/S24058 9631632300X

[5] K. Máslo and A. Kasembe, "Mitigation measures for photovoltaics retrofit", IEEE Trans. Sust. Energy, Vol.9 No.1 (Jan. 2018), pp. 333-339

[6] K. Máslo and T. Hába, "Compatibility of turbine models for stability studies", in Proc. $19^{\text {th }}$ International scientific conference Electric Power Engineering (EPE), 2018

[7] K. Máslo, "Impact of Photovoltaics on Frequency Stability of Power System During Solar Eclipse“, IEEE Trans. Pow. Syst., Vol. 31 (Sept. 2016), No. 3, pp.36483655

[8] I. Avramiotis-Falireas, P. Zolotarev, A. Khatir, M. Zima, "Analysis and comparison of secondary frequency control reserve activation rules: Pro-rata vs. merit order", in Proc. IEEE Power Systems Computation Conference, 2014

[9] The IEEE Reliability test system - 1996, IEEE Trans. Power Syst., Vol. 14, No. 3 (Aug. 1999), pp. 1010-1020 